\title{
Clinical and Biological Predictors of Plasma Levels of Soluble RAGE in Critically Ill Patients: Secondary Analysis of a Prospective Multicenter Observational Study
}

\author{
Thibaut Pranal, ${ }^{1}$ Bruno Pereira, ${ }^{2}$ Pauline Berthelin, ${ }^{1}$ Laurence Roszyk, ${ }^{3,4}$ Thomas Godet ${ }^{D},{ }^{1}$ \\ Russell Chabanne, ${ }^{1}$ Nathanael Eisenmann, ${ }^{5}$ Alexandre Lautrette, ${ }^{6}$ Corinne Belville, ${ }^{3}$ \\ Raiko Blondonnet, ${ }^{1,3}$ Sophie Cayot $\mathbb{D}^{1},{ }^{1}$ Thierry Gillart, ${ }^{1}$ Yvan Skrzypczak, ${ }^{5}$ \\ Bertrand Souweine, ${ }^{6}$ Damien Bouvier, ${ }^{3,4}$ Loic Blanchon $\left(\mathbb{D},{ }^{3}\right.$ Vincent Sapin $\left(\mathbb{D},{ }^{3,4}\right.$ \\ Jean-Michel Constantin, ${ }^{1,3}$ and Matthieu Jabaudon ${ }^{1,3}$ \\ ${ }^{1}$ Department of Perioperative Medicine, CHU Clermont-Ferrand, Clermont-Ferrand, France \\ ${ }^{2}$ Department of Clinical Research and Innovation (DRCI), CHU Clermont-Ferrand, Clermont-Ferrand, France \\ ${ }^{3}$ Université Clermont Auvergne, CNRS UMR 6293, and INSERM U1103, GReD, Clermont-Ferrand, France \\ ${ }^{4}$ Department of Medical Biochemistry and Molecular Biology, CHU Clermont-Ferrand, Clermont-Ferrand, France \\ ${ }^{5}$ Intensive Care Unit, Jean Perrin Comprehensive Cancer Center, Clermont-Ferrand, France \\ ${ }^{6}$ Medical Intensive Care Unit, UMR CNRS 6023, CHU Clermont-Ferrand, Clermont-Ferrand, France \\ Correspondence should be addressed to Matthieu Jabaudon; mjabaudon@chu-clermontferrand.fr
}

Received 24 February 2018; Accepted 11 April 2018; Published 10 May 2018

Academic Editor: Hubertus Himmerich

Copyright ( 2018 Thibaut Pranal et al. This is an open access article distributed under the Creative Commons Attribution License, which permits unrestricted use, distribution, and reproduction in any medium, provided the original work is properly cited.

\begin{abstract}
Rationale. Although soluble forms of the receptor for advanced glycation end products (RAGE) have been recently proposed as biomarkers in multiple acute or chronic diseases, few studies evaluated the influence of usual clinical and biological parameters, or of patient characteristics and comorbidities, on circulating levels of soluble RAGE in the intensive care unit (ICU) setting. Objectives. To determine, among clinical and biological parameters that are usually recorded upon ICU admission, which variables, if any, could be associated with plasma levels of soluble RAGE. Methods. Data for this ancillary study were prospectively obtained from adult patients with at least one ARDS risk factor upon ICU admission enrolled in a large multicenter observational study. At ICU admission, plasma levels of total soluble RAGE (sRAGE) and endogenous secretory (es)RAGE were measured by duplicate ELISA and baseline patient characteristics, comorbidities, and usual clinical and biological indices were recorded. After univariate analyses, significant variables were used in multivariate, multidimensional analyses. Measurements and Main Results. 294 patients were included in this ancillary study, among whom $62 \%$ were admitted for medical reasons, including septic shock (11\%), coma (11\%), and pneumonia (6\%). Although some variables were associated with plasma levels of RAGE soluble forms in univariate analysis, multidimensional analyses showed no significant association between admission parameters and baseline plasma sRAGE or esRAGE. Conclusions. We found no obvious association between circulating levels of soluble RAGE and clinical and biological indices that are usually recorded upon ICU admission. This trial is registered with NCT02070536.
\end{abstract}

\section{Introduction}

The receptor for advanced glycation end products (RAGE) is a multiligand receptor from the immunoglobulin superfamily of cell surface receptors [1,2]. Most RAGE ligands are implicated in inflammation and cell migration processes, and indeed, the expression of RAGE is low under physiological settings but can be upregulated in response to inflammation [3]. Upon RAGE stimulation, the transcription factor $\mathrm{NF}-\kappa \mathrm{B}$ is translocated to the nucleus and binds to the 
promoter region of RAGE which enhances RAGE mRNA translation itself [4]. RAGE has therefore the potential to function as a master switch capable of converting a transient proinflammatory response, evoked by an inflammatory stimulus into sustained cellular dysfunction $[5,6]$.

In addition to the full-length receptor, RAGE undergoes extensive alternative splicing to produce a variety of transcripts with diverse functions. Major isoforms are the fulllength mRAGE, a secreted form RAGE v1 (also named as endogenous secretory (es)RAGE) and an N-terminally truncated isoform RAGE v2 (previously named N-truncated RAGE). However, endogenous soluble RAGE may also be generated by mechanisms other than alternative splicing, such as membrane-associated proteases, including the sheddase A disintegrin and metalloprotease-10 (ADAM-10) and the matrix metalloproteinase-9 (MMP-9) [7-9]. Therefore, the total pool of soluble (s)RAGE is mainly composed of cleaved (c)RAGE and esRAGE isoforms. Soluble RAGE may function as a decoy for ligands, thus preventing the interaction with the membrane-anchored full-length RAGE [10]. Although the roles and regulation pathways of sRAGE are not fully understood, its circulating levels may inversely correlate with RAGE activity. The abnormal upregulation and activation of RAGEs and thereby inflammatory and immune responses are involved in the development of a number of human illnesses including diabetes, cardiovascular diseases, ischemic injury, osteoarthritis, cancer, Alzheimer's disease, and other inflammatory states $[3,11]$.

In the settings of intensive care and perioperative medicine, in which many of these diseases may interfere with acute illness, sRAGE is now considered a marker of lung epithelial injury $[12,13]$. There is growing evidence supporting a pivotal role for RAGE in the pathophysiology of acute respiratory distress syndrome (ARDS) [14] through the initiation and perpetuation of inflammatory and immune responses, but the roles of the RAGE pathway during lung injury and repair remain incompletely understood to date $[15,16]$. Notably, sRAGE has most features of a validated biomarker that could be used in clinical medicine [17], with values for ARDS diagnosis [13, 18-20], assessment of severity, impaired alveolar fluid clearance, and prognosis $[13,18$, 19, 21-23], monitoring the response to therapy [24-26] and possibly identifying subgroups (or phenotypes) of patients that could benefit from tailored therapy [23, 27]. However, more validation studies are still warranted prior to its use in clinical research practice.

The goal of this secondary analysis of prospectively acquired data was to investigate, among critically ill patients at risk of developing ARDS, the relationships between plasma levels of RAGE soluble forms (sRAGE, esRAGE) and clinical, biological variables, including common patient characteristics, coexisting conditions, and treatment.

\section{Methods}

2.1. Participants. Data used in this ancillary study were prospectively obtained from patients previously enrolled in a large multicenter observational study on the predictive values of RAGE isoforms and gene variants for the onset of ARDS (PrediRAGE study, clinicaltrials.gov identifier: NCT02070536) [28]. Between June 2014 and January 2015, 500 critically ill adult patients admitted to five intensive care units (ICUs) were enrolled in the primary study if they had at least one ARDS risk factor [14]. Patients were excluded if they were admitted for an isolated neurological or neurosurgical diagnosis without any significant medical comorbidities [29]. Patients who met the criteria for ARDS at initial assessment, or within the subsequent 24 hours, were excluded from analysis to ensure removal of ARDS that was present at baseline. Briefly, the main results from the PrediRAGE study indicate that elevated plasma sRAGE and the presence of single nucleotide polymorphism rs2070600 within AGER gene were useful to identify patients at the highest risk of developing ARDS [28].

Patients for whom full biological data set was not available at baseline were excluded from this secondary analysis. The following parameters were collected at baseline: patient characteristics (age, sex, and body mass index) and comorbidities, severity of illness as assessed by the simplified acute physiology score (SAPS II) [30, 31], respiratory and hemodynamic parameters, the ratio of the partial pressure of arterial oxygen to the fraction of inspired oxygen $\left(\mathrm{PaO}_{2} / \mathrm{FiO}_{2}\right)$, the partial pressure of carbon dioxide $\left(\mathrm{PaCO}_{2}\right)$ and other biological variables (e.g., arterial $\mathrm{pH}$, serum lactate, serum bicarbonate, serum creatinine, leukocyte, and platelets counts), concurrently administered treatments (e.g., corticosteroids and vasopressors), and the lung injury prediction score (LIPS), that is, a clinical prediction score developed with the goal of identifying patients at a high risk for the development of ARDS [32].

Our Institutional Review Board approved the research protocols for the primary study and this ancillary study (Comité de Protection des Personnes Sud Est VI, approval number AU1073). All participants, or their next of kin, provided written consent to participate. There was no deviation from the approved protocols.

2.2. Primary Outcomes. Primary outcomes of this ancillary study were plasma levels of sRAGE and esRAGE, as measured by duplicate ELISA (R\&D Systems, Minneapolis, MN, USA, and B-Bridge International Inc., Santa Clara, CA, USA, resp.) upon ICU admission.

2.3. Statistical Methods. Patient characteristics are presented as the mean ( \pm standard deviation $(\mathrm{SD})$ ) or median [interquartile range (IQR)] values for continuous data (assumption of normality assessed using the Shapiro-Wilk test) and as the number of patients and associated percentages for categorical parameters. Comparisons between independent groups were performed using the chi-squared or Fisher exact tests for categorical variables and Student $t$-test or Mann-Whitney $U$ test for quantitative parameters (normality, assumption of homoscedasticity studied using the Fisher-Snedecor test). Univariate correlations were assessed using Spearman correlation coefficients for quantitative outcomes and with Cohen's coefficients of effect sizes for qualitative variables. As proposed by some authors, we did not apply any mathematical correction to assess type I error [33]. Instead, specific 
TAble 1: Main baseline characteristics at ICU admission. Data are presented as the mean \pm standard deviation or $n(\%)$. Percentages may not exactly total $100 \%$ because of rounding. The body mass index is the weight in kilograms divided by the square of the height in meters. ICU: intensive care unit; COPD: chronic obstructive pulmonary disease; ARDS: acute respiratory distress syndrome; SAPS II: simplified acute physiology score II.

\begin{tabular}{|c|c|}
\hline Age (years) & $61.4 \pm 16$ \\
\hline Male sex & $195(66)$ \\
\hline Body mass index $\left(\mathrm{kg} \cdot \mathrm{m}^{-2}\right)$ & $26.4 \pm 7.2$ \\
\hline \multicolumn{2}{|l|}{ Primary reason for ICU admission } \\
\hline Medical & $181(62)$ \\
\hline Emergent surgery & $57(19)$ \\
\hline Planned surgery & $50(17)$ \\
\hline \multicolumn{2}{|l|}{ Coexisting chronic conditions } \\
\hline Hypertension & $117(40)$ \\
\hline Current smoking & $72(24)$ \\
\hline Dyslipidemia & $61(21)$ \\
\hline Atherosclerosis & $54(18)$ \\
\hline Diabetes & $53(18)$ \\
\hline Cancer & $48(16)$ \\
\hline COPD & $30(10)$ \\
\hline Liver cirrhosis & $18(6)$ \\
\hline Chronic renal failure requiring dialysis & $9(3)$ \\
\hline Asthma & $5(2)$ \\
\hline \multicolumn{2}{|l|}{ Diagnosis at admission } \\
\hline Septic shock & $33(11)$ \\
\hline Coma & $33(11)$ \\
\hline Pneumonia & $26(9)$ \\
\hline Brain trauma & $24(8)$ \\
\hline Intra-abdominal sepsis & $19(6)$ \\
\hline Subarachnoid hemorrhage & $19(6)$ \\
\hline Stroke & $19(6)$ \\
\hline Acute liver failure & $18(6)$ \\
\hline Abdominal surgery & $13(4)$ \\
\hline Gastrointestinal hemorrhage & $13(4)$ \\
\hline Acute kidney injury & $13(4)$ \\
\hline Status epilepticus & $13(4)$ \\
\hline Thoracic trauma & $11(4)$ \\
\hline Vascular surgery & $9(3)$ \\
\hline Neurosurgery & $9(3)$ \\
\hline Pancreatitis & $7(2)$ \\
\hline Aspiration & $6(2)$ \\
\hline Pleural effusion & $4(1)$ \\
\hline Thoracic surgery & $3(1)$ \\
\hline Acute severe asthma & $3(1)$ \\
\hline Cardiac surgery & $1(0)$ \\
\hline Kidney transplantation & $1(0)$ \\
\hline Kidney trauma & $1(0)$ \\
\hline Meningoencephalitis & $2(1)$ \\
\hline \multicolumn{2}{|l|}{ Primary ARDS risk factor } \\
\hline High-risk surgery & $108(37)$ \\
\hline
\end{tabular}

TABle 1: Continued.

\begin{tabular}{lc}
\hline Shock & $83(28)$ \\
Sepsis & $67(23)$ \\
Pneumonia & $37(13)$ \\
Severe trauma & $30(10)$ \\
Drug overdose & $9(3)$ \\
Pancreatitis & $8(3)$ \\
Aspiration & $5(2)$ \\
Lung injury prediction score (LIPS) & $5 \pm 2.5$ \\
SAPS II & $44.3 \pm 19.7$ \\
Specific treatment at admission & \\
Vasopressor use & $62(21)$ \\
Corticosteroids & $16(5)$ \\
Neuromuscular blocking agent & $2(1)$ \\
Ventilation at admission & \\
Spontaneous breathing & $150(51)$ \\
Invasive ventilation & $126(43)$ \\
Noninvasive ventilation & $18(6)$ \\
\hline
\end{tabular}

attention was given to the magnitude of improvement and to clinical relevance. A center effect was taken into account as a random effect, when appropriate.

Multivariate adjustments using multidimensional analyses (principal component and multiple correspondence analyses) were performed in order to assess relationships between the modalities of variables and to identify distinct patterns of variables, that is, clusters of variables in which groups of patients have similar characteristics.

Tests were two-sided, with a type I error set at $\alpha=0.05$. Statistical analyses were performed using Stata 14 (StataCorp LP, College Station, TX, USA) and R version 3.3.1 (R Foundation for Statistical Computing, Vienna, Austria).

\section{Results}

3.1. Baseline Characteristics. The baseline characteristics of the study sample are described in Table 1. A total of 294 patients were included in this ancillary study. Most patients (62\%) were admitted to the ICU for medical conditions, including septic shock (11\%), coma (11\%), and pneumonia (9\%). Sixty-six percent were male, with a mean age of $61.4 \pm 16$ years. Most frequent coexisting comorbidities included hypertension (40\%), current tobacco smoking (24\%), dyslipidemia (21\%), atherosclerosis (18\%), and diabetes $(18 \%)$. Primary ARDS risk factors were high-risk surgery (37\%), shock (28\%), sepsis (23\%), and pneumonia (13\%). The mean lung injury prediction score was $5 \pm 2.5$, and baseline SAPS II was $44.3 \pm 19.7 .150$ (51\%) patients were spontaneously breathing, while $43 \%$ were treated with invasive ventilation and $6 \%$ with noninvasive ventilation.

3.2. Clinical and Biological Variables at ICU Admission. Clinical and biological parameters are reported in Table 2 for the whole cohort of patients who were included in this study. In mechanically ventilated patients, median $\mathrm{PaO}_{2} / \mathrm{FiO}_{2}$ was 250 
TABle 2: Clinical, respiratory, and biological parameters at ICU admission. Data are presented as median [interquartile range]. ICU: intensive care unit; PBW: predicted body weight; $\mathrm{FiO}_{2}$ : fraction of inspired oxygen; $\mathrm{PaO}_{2}$ : arterial partial pressure of oxygen; $\mathrm{PaCO}_{2}$ : arterial partial pressure of carbon dioxide; CRP: $\mathrm{C}$-reactive protein. PINI: prognostic nutritional and inflammatory index; RAGE: receptor for advanced glycation end products; sRAGE: soluble RAGE; esRAGE: endogenous secretory RAGE.

\begin{tabular}{|c|c|}
\hline \multicolumn{2}{|l|}{ Clinical parameters } \\
\hline Heart rate $(\mathrm{bpm})$ & $86.5[70.3-104]$ \\
\hline Mean arterial pressure $(\mathrm{mmHg})$ & $78[69-88]$ \\
\hline Respiratory rate $(\mathrm{cpm})$ & $17[14-21]$ \\
\hline Temperature $\left({ }^{\circ} \mathrm{C}\right)$ & $37.0[36.5-37.4]$ \\
\hline Glasgow coma scale & $10.5[0-15]$ \\
\hline \multicolumn{2}{|l|}{ Respiratory parameters } \\
\hline Tidal volume $(\mathrm{mL})$ & $472.5[440.5-510]$ \\
\hline Tidal volume $\left(\mathrm{mL} \cdot \mathrm{kg}^{-1}\right.$ of $\left.\mathrm{PBW}\right)$ & $7.4[6.7-8.1]$ \\
\hline Positive end-expiratory pressure $\left(\mathrm{cmH}_{2} \mathrm{O}\right)$ & $7[6-8]$ \\
\hline Inspiratory plateau pressure $\left(\mathrm{cmH}_{2} \mathrm{O}\right)$ & $17[14-20]$ \\
\hline $\mathrm{FiO}_{2}(\%)$ & $36[28-50]$ \\
\hline $\mathrm{PaO}_{2}(\mathrm{mmHg})$ & $92[77-132.8]$ \\
\hline $\mathrm{PaCO}_{2}(\mathrm{mmHg})$ & $37[32-43.8]$ \\
\hline $\mathrm{pH}$ & $7.4[7.3-7.4]$ \\
\hline Serum bicarbonate $\left(\mathrm{mmol} \cdot \mathrm{L}^{-1}\right)$ & $21[18-24]$ \\
\hline $\mathrm{PaO}_{2} / \mathrm{FiO}_{2}$ & $250[154.3-300]$ \\
\hline \multicolumn{2}{|l|}{ Biological parameters } \\
\hline Serum creatinine $\left(\mu \mathrm{mol} \cdot \mathrm{L}^{-1}\right)$ & $76[56-115]$ \\
\hline Serum urea $\left(\mathrm{mmol} \cdot \mathrm{L}^{-1}\right)$ & $6.6[4.3-10]$ \\
\hline Serum sodium $\left(\mathrm{mmol} \cdot \mathrm{L}^{-1}\right)$ & $139.5[136-142]$ \\
\hline Serum potassium $\left(\mathrm{mmol} \cdot \mathrm{L}^{-1}\right)$ & $3.9[3.6-4.2]$ \\
\hline Blood leucocytes $\left(\mathrm{G} \cdot \mathrm{L}^{-1}\right)$ & $11.6[8.1-16.6]$ \\
\hline Blood platelets $\left(\mathrm{G} \cdot \mathrm{L}^{-1}\right)$ & 185 [113-247] \\
\hline $\mathrm{CRP}\left(\mathrm{mg} \cdot \mathrm{L}^{-1}\right)$ & $108[35.5-182]$ \\
\hline Serum lactate $\left(\mathrm{mmol} \cdot \mathrm{L}^{-1}\right)$ & $1.6[0.9-2.8]$ \\
\hline Serum orosomucoid $\left(\mathrm{g} \cdot \mathrm{L}^{-1}\right)$ & $1.3[0.9-1.9]$ \\
\hline Serum prealbumin $\left(\mathrm{g} \cdot \mathrm{L}^{-1}\right)$ & $0.1[0.1-0.2]$ \\
\hline Serum albumin $\left(\mathrm{g} \cdot \mathrm{L}^{-1}\right)$ & $26.1[22-30.9]$ \\
\hline PINI & $36.8[8.6-167.9]$ \\
\hline \multicolumn{2}{|l|}{ RAGE soluble forms } \\
\hline sRAGE $\left(\mathrm{pg} \cdot \mathrm{mL}^{-1}\right)$ & 1006 [638-1993] \\
\hline esRAGE $\left(\mathrm{pg} \cdot \mathrm{mL}^{-1}\right)$ & $470[202-1000]$ \\
\hline
\end{tabular}

[154-300], with an inspiratory plateau pressure of 17 [14-20] $\mathrm{cmH}_{2} \mathrm{O}$ and positive end-expiratory pressure (PEEP) set at 7 [6-8] $\mathrm{cmH}_{2} \mathrm{O}$. Tidal volume was $7.4[6.7-8.1] \mathrm{mL} \cdot \mathrm{kg}^{-1}$ of predicted body weight. C-reactive protein at admission was 108 [35.5-182] $\mathrm{mg} \cdot \mathrm{L}^{-1}$. Baseline plasma levels of sRAGE and esRAGE were 1006 [638-1993] and 470 [202-1000] $\mathrm{pg} \cdot \mathrm{L}^{-1}$, respectively.

3.3. Univariate Analyses of Quantitative Variables. Correlations between sRAGE levels and other quantitative variables were analyzed using Spearman correlation coefficients.
Spearman coefficients of correlation (rho) are reported in Figure 1. Weak-to-moderate associations were considered when coefficients were above 0.3. Serum creatinine, urea, and potassium had weak positive correlations with plasma sRAGE, while serum sodium correlated negatively with baseline sRAGE. No other quantitative variable was associated with levels of sRAGE in univariate analysis.

Baseline severity of illness (as assessed by SAPS II), heart rate, respiratory rate, PEEP, serum urea, potassium, and lactate correlated positively, albeit modestly, with plasma levels of esRAGE (Figure 2). Arterial pH, serum bicarbonate, and $\mathrm{PaO}_{2} / \mathrm{FiO}_{2}$ negatively correlated with plasma esRAGE. No other quantitative variable was associated with plasma esRAGE in univariate analysis.

3.4. Univariate Analyses of Qualitative Variables. Qualitative variables were analyzed based on effect size calculations. Figures 3 and 4 summarize Cohen's $d$ coefficients of effect sizes (with SD) of qualitative variables when tested against plasma sRAGE and esRAGE, respectively. Weak-tomoderate associations were again considered when coefficients were above 0.3 .

When tested against plasma sRAGE, variables that had effect size coefficients above 0.3 and $95 \%$ CI excluding 0 (i.e., variables with significant associations) were as follows:1 a medical history of atherosclerosis or of chronic renal failure requiring dialysis, ICU admission for medical reasons in general, and ICU admission for pneumonia, stroke, pancreatitis and aspiration, and severe trauma, after high-risk surgery and after abdominal surgery. Such variables were all negatively associated with plasma sRAGE, except stroke, pancreatitis, high risk, and abdominal surgeries (Figure 3).

Variables that were significantly, and negatively, associated with plasma esRAGE were baseline ongoing treatment with corticosteroids and ICU admission for aspiration or pneumonia (Figure 4).

3.5. Multidimensional Analyses. Next, we performed multidimensional analyses in order to identify selected variables (i.e., significant in univariate analyses) that best correlated with baseline plasma sRAGE or esRAGE levels. The main objective was therefore to compute two-dimensional graphs with multivariate datasets of variables and then to verify whether such datasets were associated with plasma levels of RAGE soluble forms.

We first included selected variables (based on the results from univariate analysis) against log-transformed plasma sRAGE in a principal component analysis (PCA) (Figure 5(a)). The first two axes of PCA were chosen as they represent $31 \%$ of total inertia and because including other axes did not influence the results (data not shown). Based on the horizontal axis, patients admitted after abdominal or high-risk surgery were well discriminated from medical patients and those admitted with aspiration, pneumonia, or pancreatitis. The most obvious result from this PCA is that baseline log-transformed sRAGE seems rather well isolated from other variables, thus suggesting an absence of correlation with selected variables. However, the vector for sRAGE is directed in the same way than the vector for kidney- 


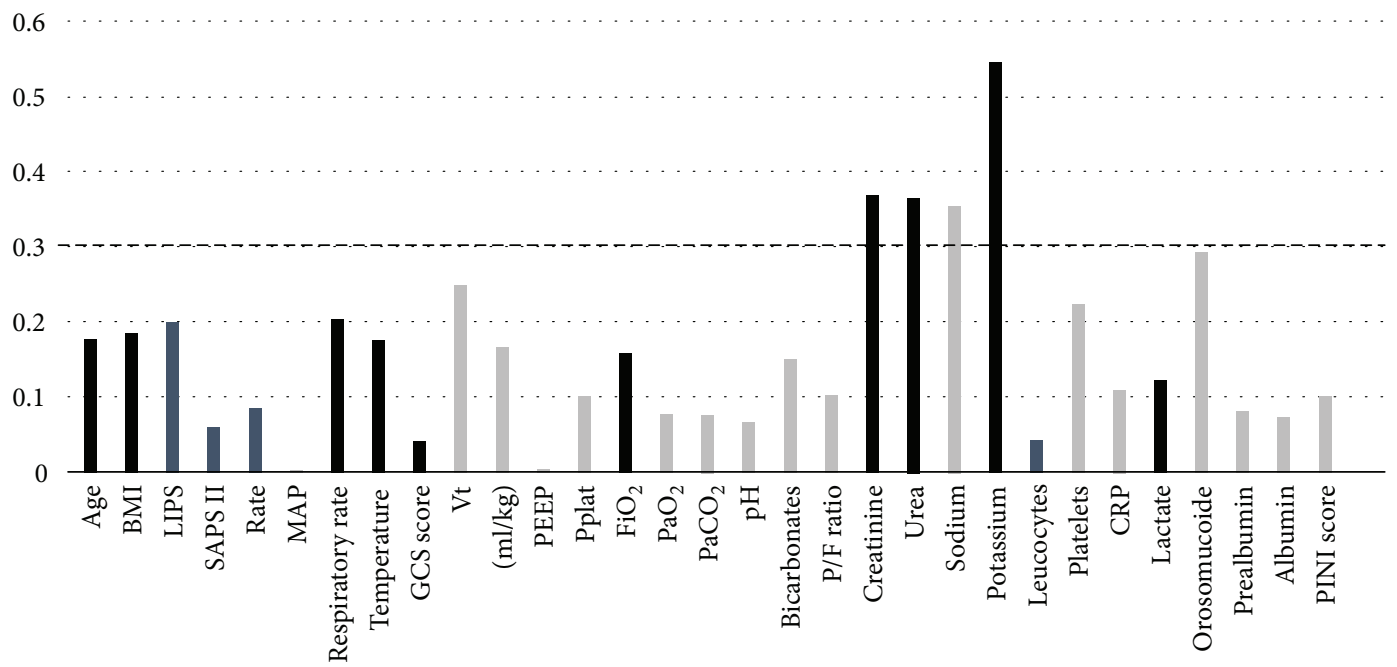

FIGURE 1: Spearman rho coefficients of the correlation between quantitative variables and plasma sRAGE at ICU admission. Dark bars represent positive correlations; grey bars represent negative correlations. The body mass index (BMI) is the weight in kilograms divided by the square of the height in meters. LIPS: lung injury prediction score; SAPS II: simplified acute physiology score II; MAP: mean arterial

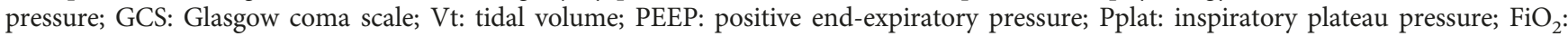
fraction of inspired oxygen; $\mathrm{PaO}_{2}$ : arterial partial pressure of oxygen; $\mathrm{PaCO}_{2}$ : arterial partial pressure of carbon dioxide; $\mathrm{P} / \mathrm{F}$ ratio: $\mathrm{PaO} \mathrm{O}_{2}$ / $\mathrm{FiO}_{2}$; CRP: C-reactive protein; PINI: prognostic nutritional and inflammatory index; ICU: intensive care unit; sRAGE: soluble form of the receptor for advanced glycation end products.

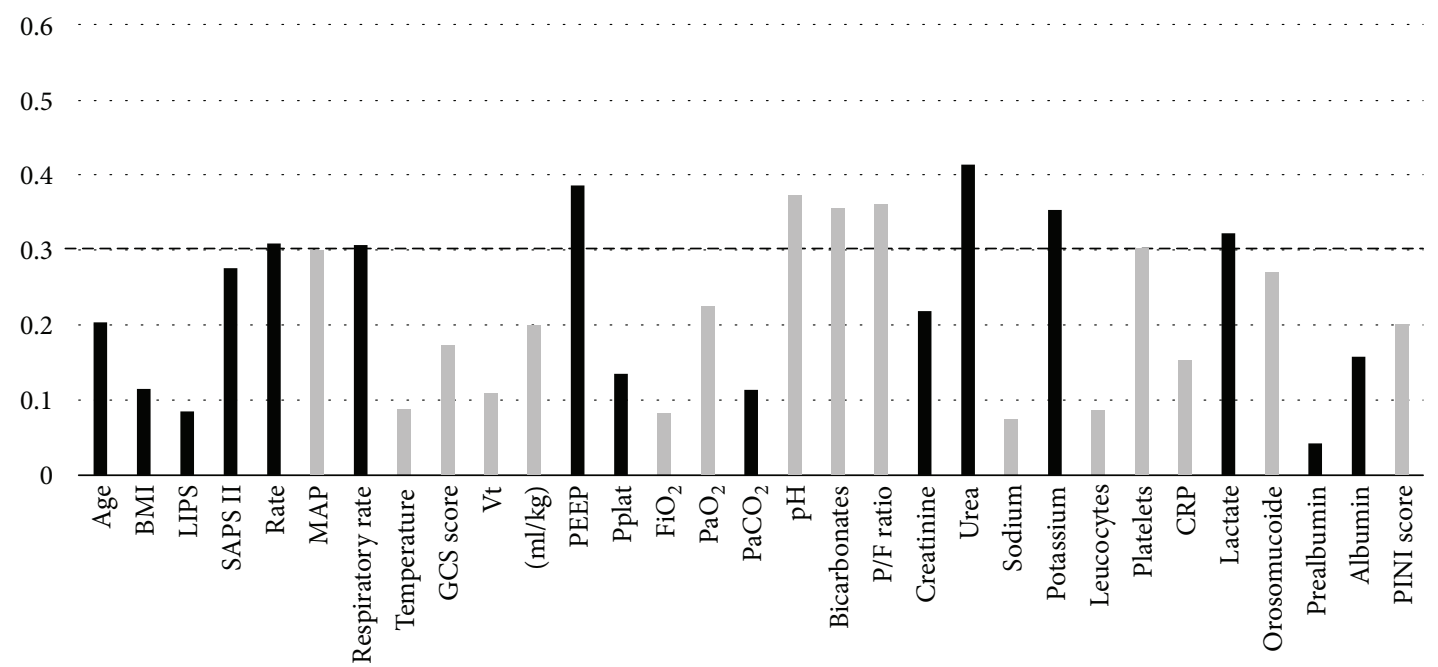

FIGURE 2: Spearman rho coefficients of correlation between quantitative variables and plasma esRAGE at ICU admission. Dark bars represent positive correlations; grey bars represent negative correlations. The body mass index (BMI) is the weight in kilograms divided by the square of the height in meters. LIPS: lung injury prediction score; SAPS II: simplified acute physiology score II; MAP: mean arterial pressure; GCS: Glasgow coma scale; Vt: tidal volume; PEEP: positive end-expiratory pressure; Pplat: inspiratory plateau pressure; FiO ${ }_{2}$ : fraction of inspired oxygen; $\mathrm{PaO}_{2}$ : arterial partial pressure of oxygen $\mathrm{PaCO}_{2}$ : arterial partial pressure of carbon dioxide; $\mathrm{P} / \mathrm{F}$ ratio: $\mathrm{PaO} / \mathrm{FiO}$; $\mathrm{CRP}$ : C-reactive protein; PINI: prognostic nutritional and inflammatory index; ICU: intensive care unit; ICU: intensive care unit; esRAGE: endogenous secretory form of the receptor for advanced glycation end products.

related variables (such as urea, serum creatinine, and a history of chronic renal failure), although these variables may exhibit multicollinearity. Such an association with kidneyrelated variables was not confirmed when sRAGE was considered an independent variable in PCA.

We also performed another multidimensional analysis (multiple correspondence analysis (MCA)) using quartiles of plasma sRAGE instead of using its log-transformed values
(Figure 5(b)). Again, sRAGE was not obviously associated with other selected variables. However, lowest values of sRAGE (i.e., 1st quartile) were separated from those of other quartiles and were slightly, yet insignificantly, related to pancreatitis and stroke as admission diagnoses.

Using the same methodology, we performed PCA against log-transformed plasma esRAGE (Figure 6(a)), with the first two axes representing $26 \%$ of total inertia. As against sRAGE, 

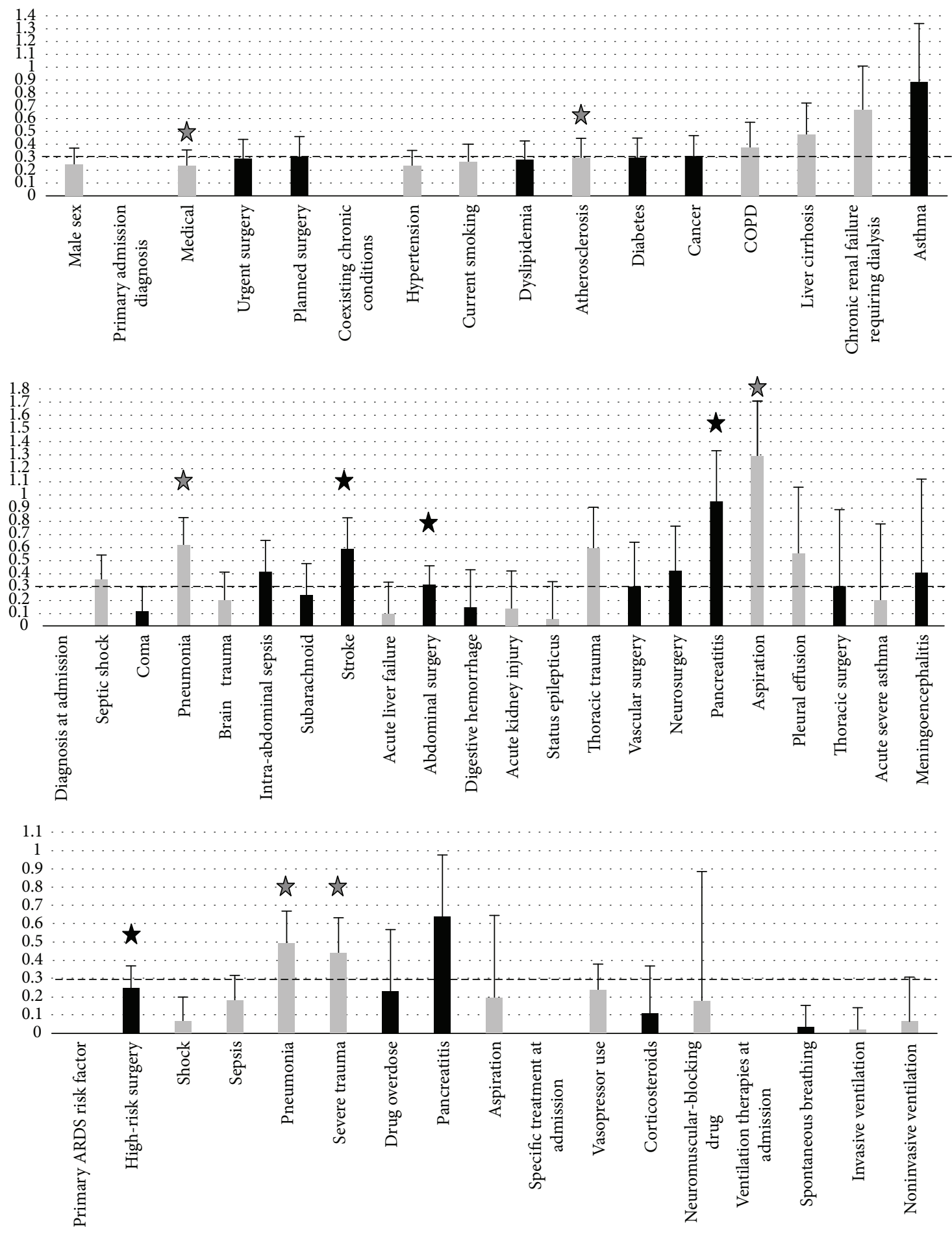

Figure 3: Size effect coefficient (Cohen's $d$ coefficient), with upper standard deviation (SD) for baseline qualitative variables tested against plasma sRAGE at ICU admission. Dark bars represent positive values for size effect, grey bars represent negative values, and stars represent coefficient values with $95 \%$ confidence intervals that exclude 0 , i.e. statistical significance. sRAGE: soluble form of the receptor for advanced glycation end products. ICU: intensive care unit. COPD: chronic obstructive pulmonary disease.

including other axes did not influence the results (data not shown). Results showed great heterogeneity, suggesting the absence of associations between esRAGE and selected variables, except for ongoing treatment with corticosteroids. However, only 2 patients from our cohort received such treatment upon ICU admission, thus supporting statistical insignificance in PCA. This association was not found when esRAGE was computed as an independent variable.

Finally, we performed multidimensional analysis using quartiles of plasma sRAGE instead of its log-transformed 

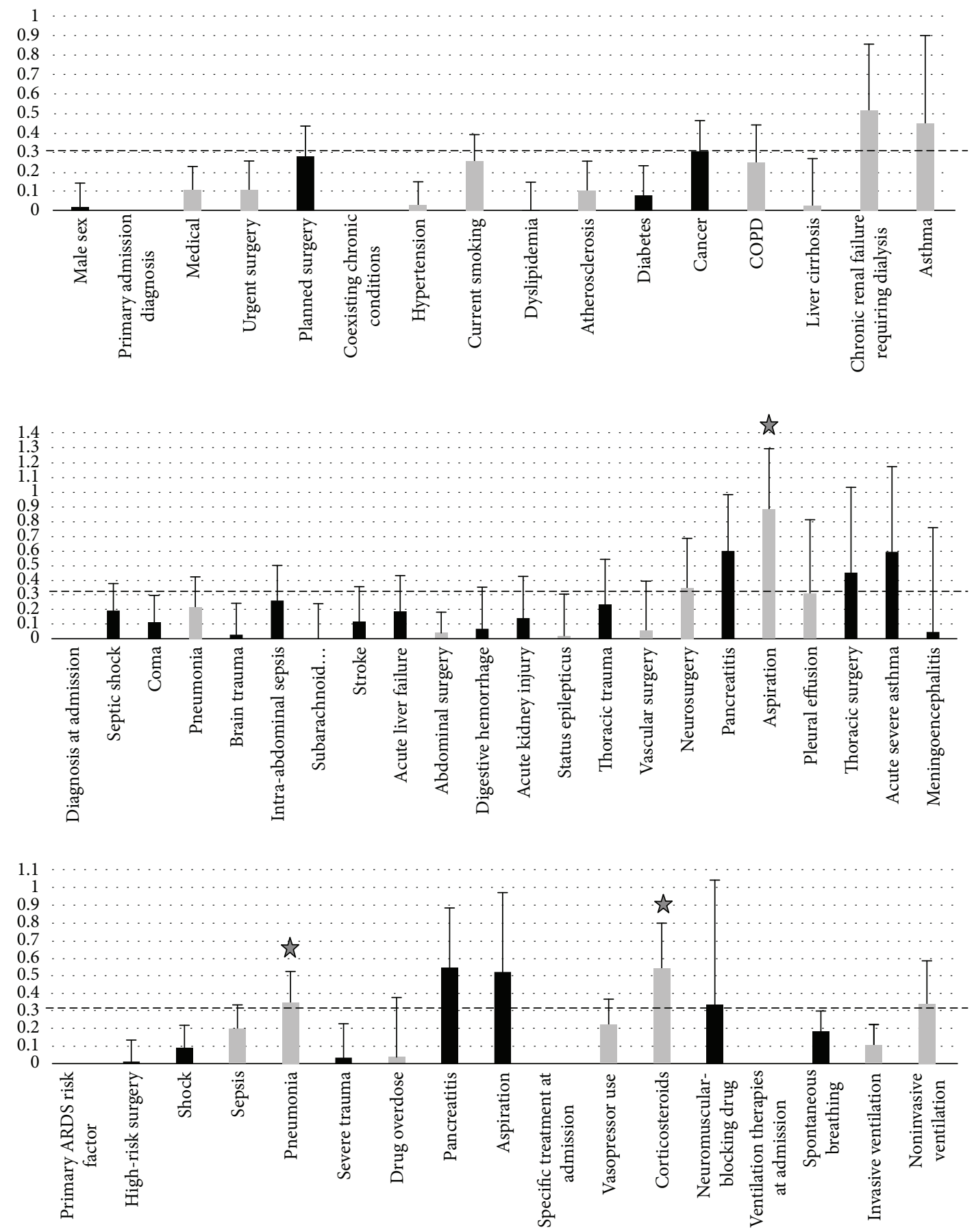

FIGURE 4: Size effect coefficient (Cohen's $d$ coefficient), with upper standard deviation (SD) for baseline qualitative variables tested against plasma esRAGE at ICU admission. Dark bars represent positive values for size effect, grey bars represent negative values, and stars represent coefficient values with $95 \%$ confidence intervals that exclude 0 , that is, statistical significance. esRAGE: endogenous secretory form of the receptor for advanced glycation end products; ICU: intensive care unit; COPD: chronic obstructive pulmonary disease.

values (Figure 6(b)) that confirmed the absence of an association between quartiles of esRAGE and other variables.

\section{Discussion}

In this secondary analysis of prospectively acquired data in a sample of 294 critically ill patients, we aimed at exploring putative associations between plasma levels of RAGE soluble forms (sRAGE, esRAGE) upon ICU admission and baseline demographics, clinical, biological, or therapeutic parameters. All patients from our cohort had at least one identified risk factors of ARDS, and most of them were admitted to the ICU for medical reasons (e.g., septic shock, pneumonia, and coma).

After multivariate adjustment, no significant association was found in this cohort between sRAGE, or esRAGE, and 


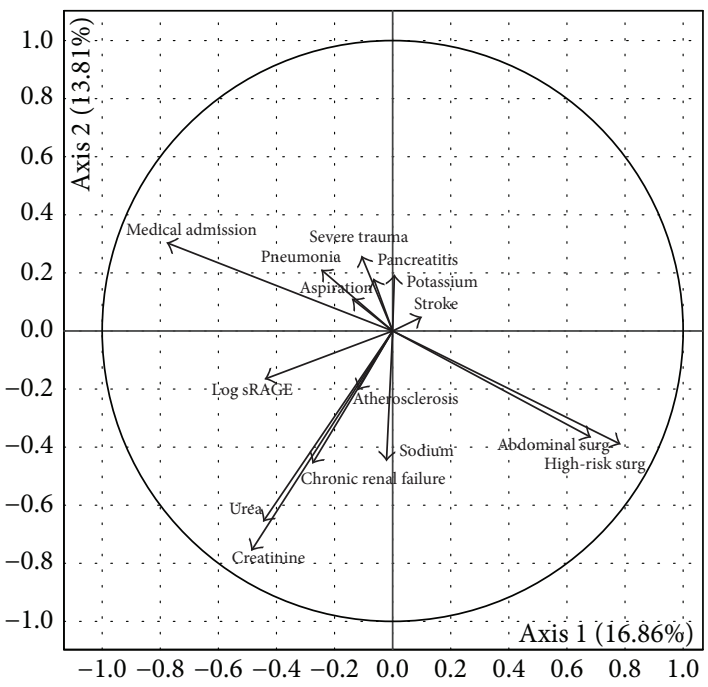

(a)

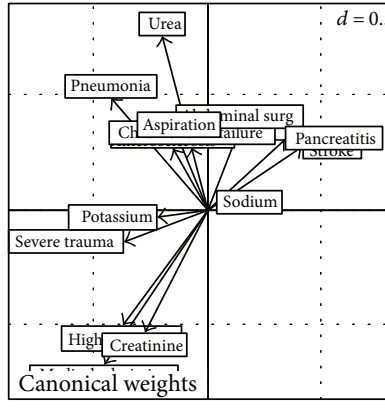

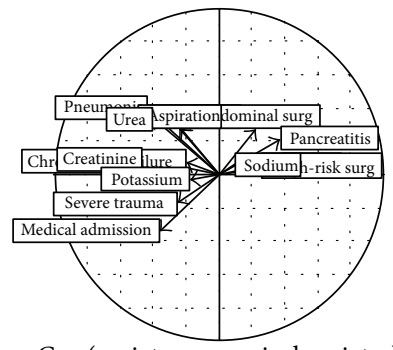

Cos (variates, canonical variates) eigenvalues $\times 1$

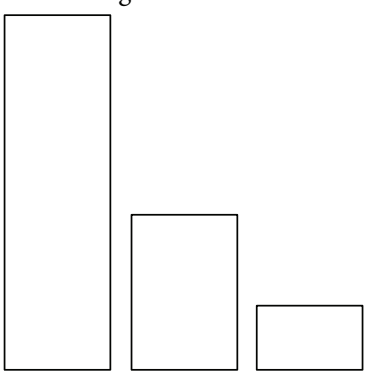

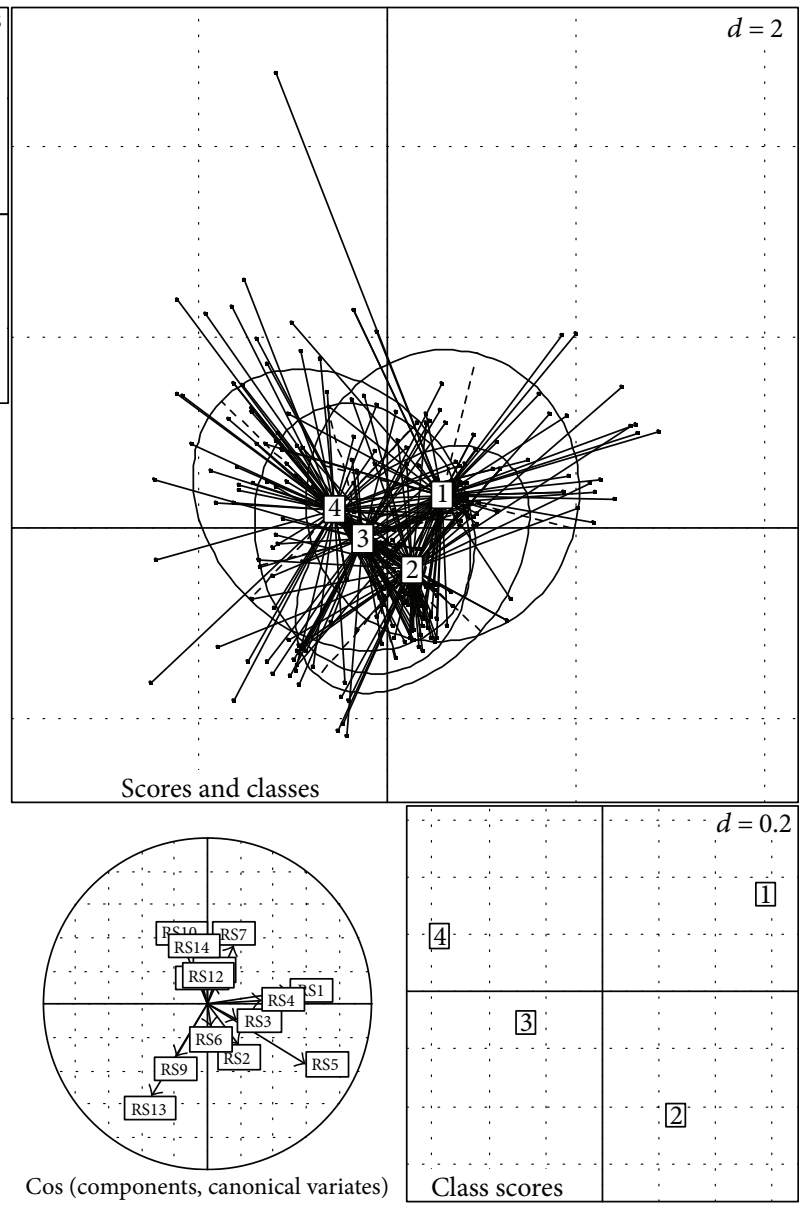

(b)

Figure 5: Multidimensional analyses. (a) Principal component analysis (PCA) of clinical and biological variables (significant in univariate analysis) against log-transformed plasma sRAGE. The first two axes of PCA were chosen, as they represent $31 \%$ of total inertia and because including other axes did not influence the results (data not shown). PCA suggests an absence of correlation between plasma sRAGE and selected variables. (b) Multiple correspondence analysis (MCA) with mixed quantitative and qualitative variables against plasma sRAGE as subdivided into quartiles. No significant association between quartiles of sRAGE and selected variables was found. [1], [2], [3], and [4] represent the 1st, 2nd, 3rd, and 4th quartiles, respectively. sRAGE: soluble form of the receptor for advanced glycation end products. 


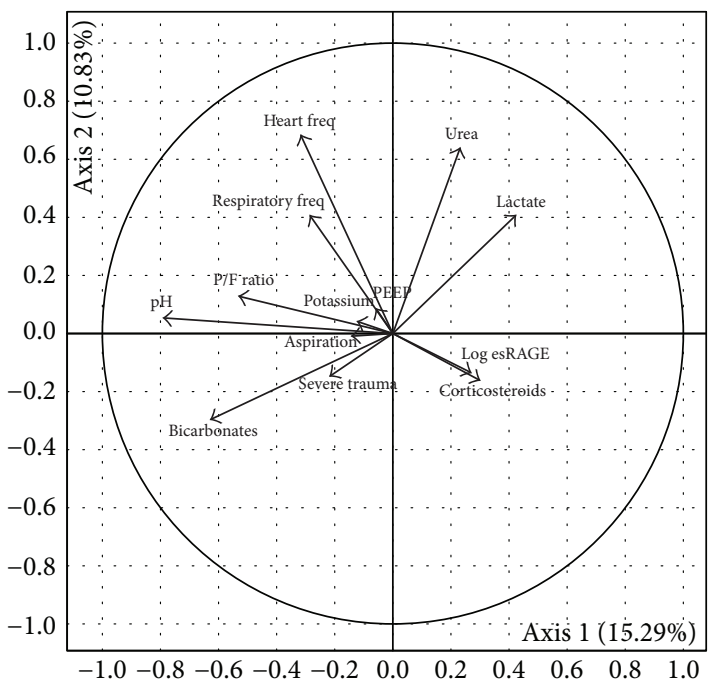

(a)

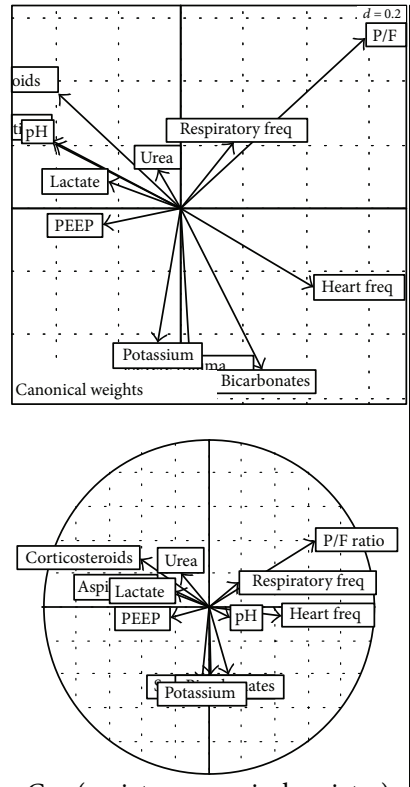

Cos (variates, canonical variates) eigenvalues $\times 1$
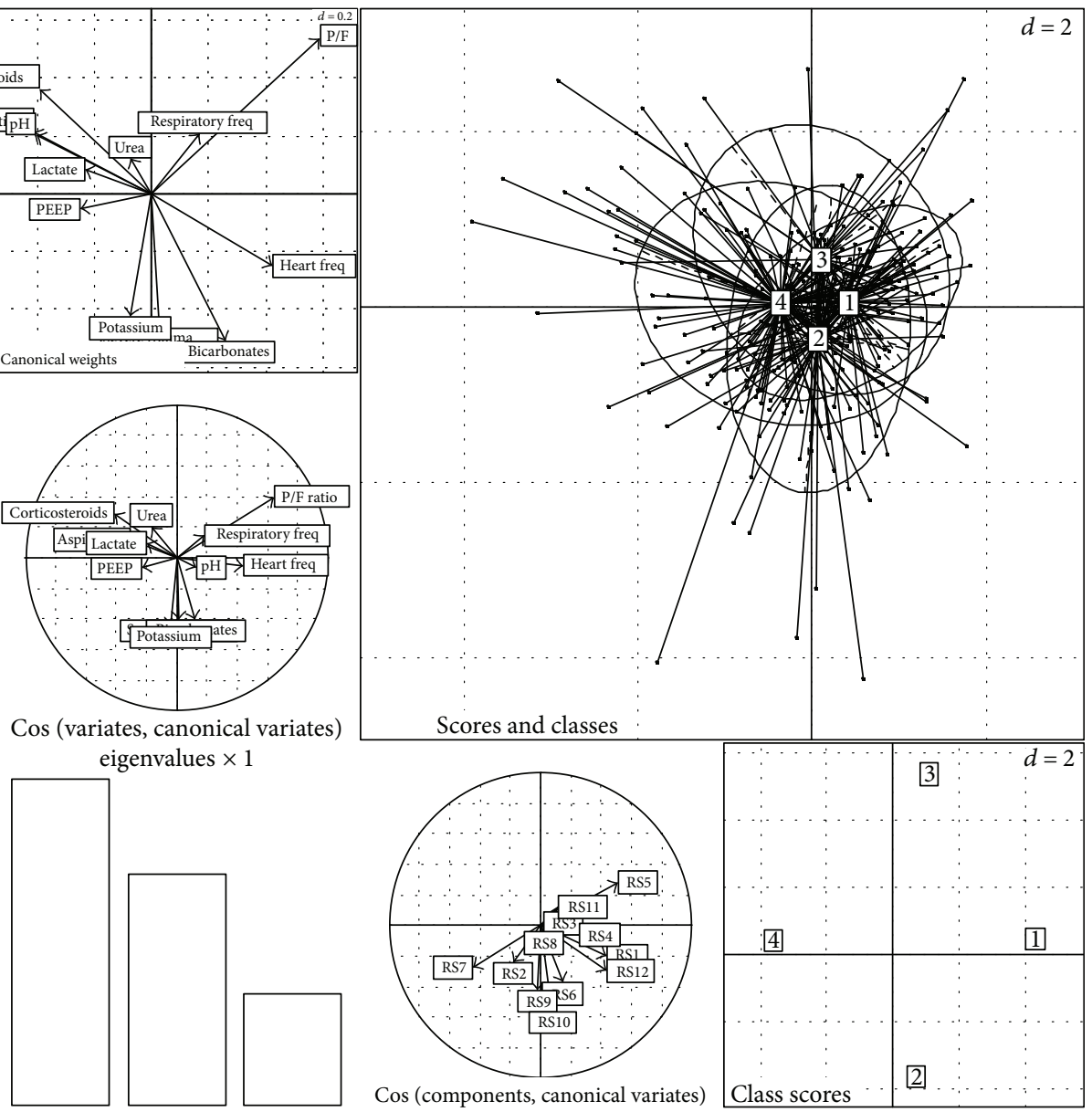

(b)

FIGURE 6: Multidimensional analyses. (a) Principal component analysis (PCA) of clinical and biological variables (significant in univariate analysis) against log-transformed plasma esRAGE. The first two axes of PCA were chosen as they represent $26 \%$ of total inertia, and because including other axes did not influence the results (data not shown). PCA suggests an absence of correlation between plasma esRAGE and selected variables. (b) Multiple correspondence analysis (MCA) with mixed quantitative and qualitative variables against plasma esRAGE as subdivided into quartiles. No significant association between quartiles of esRAGE and selected variables was found. [1], [2], [3], and [4] represent the 1st, 2nd, 3rd, and 4th quartiles, respectively. esRAGE: endogenous secretory form of the receptor for advanced glycation end products. 
patient characteristics, clinical/biological indices, or therapeutic measures at admission. In univariate analyses, ICU admission for stroke and pancreatitis and after high risk (e.g., abdominal) surgery, as well as high plasma creatinine, urea, and potassium, were factors that were most associated with higher baseline plasma sRAGE, whereas patients admitted to the ICU with pneumonia, aspiration, severe trauma, a medical history of atherosclerosis, and higher plasma sodium levels were more likely to have lower plasma sRAGE. However, such associations were insignificant after multidimensional analysis, thus suggesting no evident association between baseline plasma sRAGE and the main clinical or biological variables that were tested in this study. Admission for pneumonia or aspiration, ongoing treatment with corticosteroids, and higher baseline $\mathrm{PaO}_{2} / \mathrm{FiO}_{2}$, arterial $\mathrm{pH}$ or serum bicarbonate were factors that were associated with lower plasma esRAGE in univariate analyses, whereas higher baseline plasma levels of esRAGE were found in patients with higher SAPS II severity scores, higher heart and respiratory rates, higher levels of PEEP, or higher serum urea, potassium, and lactate. Again, however, multidimensional analyses did not reveal a significant interaction between these factors and baseline plasma esRAGE.

The ligation of RAGE is considered a double-edged sword, which may not only play an important role in resolving the pathogenesis of an offending insult but also lead to tissue destruction [34]. In particular, the balance between isoforms of RAGE has been described as an important regulator of RAGE activation both under physiological conditions and in diseases $[2,35]$. Generally, membrane-bound (m)RAGE is thought to promote disease pathogenesis and injury by activating the NF- $\kappa \mathrm{B}$ pathway. In contrast, sRAGE is thought to be protective by preventing mRAGE signaling in diseases such as tumor growth, metastasis, and diabetic wound healing [36-40]. For example, RAGE expression is upregulated in lung epithelial cells during ARDS; sRAGE (including esRAGE) is secreted into the BAL and is detectable in the serum, serving as a biomarker for the degree of lung injury and acting as a decoy receptor to downregulate the injurious pulmonary inflammatory response [22, 41, 42]. In addition, circulating RAGE soluble isoforms are modified differentially in patients with ARDS, with decreased levels of esRAGE (produced through alternate splicing [43]) and increased sRAGE, mainly through mRAGE cleavage by upregulated matrix metalloproteinases $[9,44]$, thus illustrating the complexity of the regulation of the RAGE pathway during acute illness.

Many studies have focused on the roles of the RAGE pathway in the development of diseases, in which RAGE soluble forms sRAGE and esRAGE were investigated as biomarkers and/or surrogates for prognosis. Significant associations that were found in our univariate analyses are consistent with previous reports, as they could emphasize the roles of the RAGE pathway in infectious conditions and kidney, lung, and vascular diseases. To our knowledge, our study is the first to focus on predictors of sRAGE and esRAGE in a population of critically ill patients, although previous studies have reported associations between acute illness and RAGE soluble forms. In particular, there are some discrepancies between findings from studies of circulating levels of sRAGE during sepsis: although plasma RAGE may be higher in patients with severe sepsis or septic shock than in nonseptic patients [45], sRAGE might be more of a marker of lung injury during sepsis than a marker of sepsis itself [19]. Indeed, plasma sRAGE was also higher in patients developing ARDS, regardless of the presence or absence of severe sepsis, and correlated with lung injury severity, impaired alveolar fluid clearance, and prognosis $[13,18,19,22,23,46]$. In another inflammatory condition such as acute pancreatitis, higher plasma sRAGE was associated with more severe forms of the disease, but whether the time between pancreatitis onset and sample collection may have influenced these results remains unclear [47]. Interestingly, we found no association of plasma levels of sRAGE or esRAGE with indices of inflammation (e.g., CRP, orosomucoid) and of nutritional status (e.g., prealbumin and albumin) or with the prognostic nutritional and inflammatory index (PINI) in our study, although previous studies have suggested relationships between nutrition, for example, with high intakes of dietary AGEs, and the activation of the RAGE pathway [48-50].

Elevated on-admission sRAGE was associated with an increased risk of developing kidney failure in surgical ICU patients [51], an association that had previously been described in a noncritically ill, nondiabetic, hypertensive population [52]. Such findings may explain, at least partially, why a medical history of chronic renal failure or levels of urea and creatinine had a mild correlation with plasma sRAGE after univariate analysis in our study. In other studies, circulating sRAGE was an independent predictor of cardiovascular events in patients with type 2 diabetes, with contradictory results on whether higher plasma sRAGE was more likely to be associated with stroke and/or with coronary heart disease $[53,54]$. In addition, elevated plasma sRAGE was associated with plaque vulnerability in patients with acute myocardial infarction [55]. Probably in line with these results, we found a weak correlation between stroke, as a reason for ICU admission, and sRAGE levels after univariate analysis in our study, but this association was not confirmed after multidimensional analysis. In our cohort, a medical history of diabetes was not predictive of plasma sRAGE or esRAGE. There has been extensive research on sRAGE and esRAGE in patients with type 2 diabetes, and lower levels of both sRAGE and esRAGE may be markers of poor glycemic control [56] and of increased risk of microvascular complications [57]. However, whether elevated sRAGE is associated with a higher or lower risk of cardiovascular risk during diabetes remains controversial $[53,56]$, and contradictory findings from previous studies may be explained by rather small sample sizes that may have hampered the detection of clinically relevant effect sizes [58]. In addition, studies of RAGE isoforms in health and diseases should also ideally integrate the roles of ethnicity [59] and of RAGE gene variants [60].

This study has some limitations. First, this was a secondary analysis of a large multicenter observational study. Therefore, it may not be powered enough to avoid a type II error, and the selection of potential confounders was limited to 
clinical data collected by the original study. Second, it included a selected population of critically ill patients with heterogeneous ARDS risk factors, such as high-risk surgery, shock, sepsis, and pneumonia. Therefore, whether our findings could be extrapolated to a broader population of ICU patients remains unknown. Third, our exploratory study lacks a validation cohort, and future studies remain necessary to validate our findings. Fourth, the usual caveat of the precise timing between data collection and blood sampling also applies to our study, although samples obtained more than 6 hours after ICU admission were excluded from analyses. Finally, as we chose to focus only on sRAGE and esRAGE, our study does not provide insights into the influence of admission parameters on circulating levels of RAGE ligands or on other RAGE isoforms [61]. In addition, the influence of circulating levels of RAGE ligands on those of sRAGE and esRAGE was out of the scope of this study.

This study also has several strengths. First, this is to our knowledge the first report, in a large multicenter cohort of 294 patients, of the absence of significant associations between clinical/biological parameters and plasma levels of RAGE soluble forms in the setting of critical illness. Despite limitations, our findings may add novel insights into the characterization of sRAGE and esRAGE as biomarker candidates in critically ill patients, at least because no significant association was found between plasma sRAGE/esRAGE and the main baseline patient characteristics, coexisting conditions, and clinical/biological variables. Second, another strength of this study is its statistical approach that does not primarily focus on $P$ values, but rather on coefficients of correlation (for quantitative variables) and effect sizes (for qualitative/categorical variables). Using multidimensional analyses, we were able to provide global and graphic views of patterns of variables that may be associated together, although the main limitation of such approach is the statistical influence of variables that are only present in a few numbers of patients (e.g., as for pancreatitis, aspiration, or treatment with corticosteroids in our cohort). However, and taken together, such findings on the (absence of) association between RAGE soluble forms and main admission parameters in critically ill patients should be useful to inform further studies of RAGE isoforms in this specific population.

In conclusion, this study is the first to investigate putative associations between plasma levels of RAGE main soluble forms (sRAGE and esRAGE) and multiple baseline parameters in a large cohort of patients at the risk of lung injury and ARDS, previously enrolled in a prospective multicenter observational study. Using multidimensional analyses, no significant association was found between plasma sRAGE or esRAGE, as measured upon ICU admission, and main patient characteristics, comorbidities, ongoing treatments, or usual clinical and biological variables. Such findings may encourage further studies of plasma levels of RAGE soluble forms as markers of acute diseases.

\section{Data Availability}

The data used to support the findings of this study are available from the corresponding author upon request.

\section{Disclosure}

The funders had no influence in the study design, conduct, and analysis or in the preparation of this article.

\section{Conflicts of Interest}

The authors declare that there is no conflict of interest regarding the publication of this paper.

\section{Acknowledgments}

The authors wish to thank the nurses and staff from the participating intensive care units, the technicians and staff from the Department of Medical Biochemistry and Molecular Biology, CHU Clermont-Ferrand, and from the Université d'Auvergne in Clermont-Ferrand, France. This work was supported by grants from the Conseil Régional d'Auvergne ("Programme Nouveau Chercheur de la Région Auvergne" 2013), the French National Agency for Research, the Direction Générale de l'Offre de Soins ("Programme de Recherche Translationnelle en Santé" ANR-13-PRTS-0010), and Clermont-Ferrand University Hospital ("Appel d'Offre Interne 2013," CHU Clermont-Ferrand).

\section{References}

[1] G. P. Sims, D. C. Rowe, S. T. Rietdijk, R. Herbst, and A. J. Coyle, "HMGB1 and RAGE in inflammation and cancer," Annual Review of Immunology, vol. 28, no. 1, pp. 367-388, 2010.

[2] A. M. Schmidt, S. D. Yan, S. F. Yan, and D. M. Stern, “The biology of the receptor for advanced glycation end products and its ligands," Biochimica et Biophysica Acta (BBA) - Molecular Cell Research, vol. 1498, no. 2-3, pp. 99-111, 2000.

[3] R. Ramasamy, S. F. Yan, and A. M. Schmidt, "RAGE: therapeutic target and biomarker of the inflammatory response-the evidence mounts," Journal of Leukocyte Biology, vol. 86, no. 3, pp. 505-512, 2009.

[4] J. Li and A. M. Schmidt, "Characterization and functional analysis of the promoter of RAGE, the receptor for advanced glycation end products," Journal of Biological Chemistry, vol. 272, no. 26, pp. 16498-16506, 1997.

[5] A. M. Schmidt, S. D. Yan, S. F. Yan, and D. M. Stern, "The multiligand receptor RAGE as a progression factor amplifying immune and inflammatory responses," The Journal of Clinical Investigation, vol. 108, no. 7, pp. 949-955, 2001.

[6] A. Bierhaus, S. Schiekofer, M. Schwaninger et al., "Diabetesassociated sustained activation of the transcription factor nuclear factor- $\kappa$ B," Diabetes, vol. 50 , no. 12 , pp. $2792-2808$, 2001.

[7] A. Raucci, S. Cugusi, A. Antonelli et al., "A soluble form of the receptor for advanced glycation endproducts (RAGE) is produced by proteolytic cleavage of the membrane-bound form by the sheddase a disintegrin and metalloprotease 10 (ADAM10)," The FASEB Journal, vol. 22, no. 10, pp. 37163727, 2008.

[8] E. Parkin and B. Harris, "A disintegrin and metalloproteinase (ADAM)-mediated ectodomain shedding of ADAM10," Journal of Neurochemistry, vol. 108, no. 6, pp. 1464-1479, 2009. 
[9] L. Zhang, M. Bukulin, E. Kojro et al., "Receptor for advanced glycation end products is subjected to protein ectodomain shedding by metalloproteinases," Journal of Biological Chemistry, vol. 283, no. 51, pp. 35507-35516, 2008.

[10] F. Santilli, N. Vazzana, L. G. Bucciarelli, and G. Davì, "Soluble forms of RAGE in human diseases: clinical and therapeutical implications," Current Medicinal Chemistry, vol. 16, no. 8, pp. 940-952, 2009.

[11] A. Bierhaus and P. P. Nawroth, "Multiple levels of regulation determine the role of the receptor for AGE (RAGE) as common soil in inflammation, immune responses and diabetes mellitus and Its complications," Diabetologia, vol. 52, no. 11, pp. 2251-2263, 2009.

[12] M. Shirasawa, N. Fujiwara, S. Hirabayashi et al., "Receptor for advanced glycation end-products is a marker of type I lung alveolar cells," Genes to Cells, vol. 9, no. 2, pp. 165-174, 2004.

[13] T. Uchida, M. Shirasawa, L. B. Ware et al., "Receptor for advanced glycation end-products is a marker of type I cell injury in acute lung injury," American Journal of Respiratory and Critical Care Medicine, vol. 173, no. 9, pp. 1008-1015, 2006.

[14] The ARDS Definition Task Force, "Acute respiratory distress syndrome: the Berlin Definition," JAMA, vol. 307, no. 23, pp. 2526-2533, 2012.

[15] W. A. Guo, P. R. Knight, and K. Raghavendran, "The receptor for advanced glycation end products and acute lung injury/ acute respiratory distress syndrome," Intensive Care Medicine, vol. 38, no. 10, pp. 1588-1598, 2012.

[16] T. K. Mukherjee, S. Mukhopadhyay, and J. R. Hoidal, "Implication of receptor for advanced glycation end product (RAGE) in pulmonary health and pathophysiology," Respiratory Physiology \& Neurobiology, vol. 162, no. 3, pp. 210-215, 2008.

[17] P. Ray, Y. Le Manach, B. Riou, and T. T. Houle, "Statistical evaluation of a biomarker," Anesthesiology, vol. 112, no. 4, pp. 1023-1040, 2010.

[18] M. Jabaudon, R. Blondonnet, L. Roszyk et al., "Soluble forms and ligands of the receptor for advanced glycation endproducts in patients with acute respiratory distress syndrome: an observational prospective study," PLoS One, vol. 10, no. 8, article e0135857, 2015.

[19] M. Jabaudon, E. Futier, L. Roszyk et al., "Soluble form of the receptor for advanced glycation end products is a marker of acute lung injury but not of severe sepsis in critically ill patients," Critical Care Medicine, vol. 39, no. 3, pp. 480-488, 2011.

[20] T. Mauri, S. Masson, A. Pradella et al., "Elevated plasma and alveolar levels of soluble receptor for advanced glycation endproducts are associated with severity of lung dysfunction in ARDS patients," The Tohoku Journal of Experimental Medicine, vol. 222, no. 2, pp. 105-112, 2010.

[21] R. Briot, J. A. Frank, T. Uchida, J. W. Lee, C. S. Calfee, and M. A. Matthay, "Elevated levels of the receptor for advanced glycation end products, a marker of alveolar epithelial type I cell injury, predict impaired alveolar fluid clearance in isolated perfused human lungs," Chest, vol. 135, no. 2, pp. 269-275, 2009.

[22] M. Jabaudon, R. Blondonnet, L. Roszyk et al., "Soluble receptor for advanced glycation end-products predicts impaired alveolar fluid clearance in acute respiratory distress syndrome," American Journal of Respiratory and Critical Care Medicine, vol. 192, no. 2, pp. 191-199, 2015.
[23] S. Mrozek, M. Jabaudon, S. Jaber et al., "Elevated plasma levels of sRAGE are associated with nonfocal CT-based lung imaging in patients with ARDS: a prospective multicenter study," Chest, vol. 150, no. 5, pp. 998-1007, 2016.

[24] M. Jabaudon, N. Hamroun, L. Roszyk et al., "Effects of a recruitment maneuver on plasma levels of soluble RAGE in patients with diffuse acute respiratory distress syndrome: a prospective randomized crossover study," Intensive Care Medicine, vol. 41, no. 5, pp. 846-855, 2015.

[25] M. Jabaudon, E. Futier, L. Roszyk, V. Sapin, B. Pereira, and J. M. Constantin, "Association between intraoperative ventilator settings and plasma levels of soluble receptor for advanced glycation end-products in patients without pre-existing lung injury," Respirology, vol. 20, no. 7, pp. 1131-1138, 2015.

[26] M. Jabaudon, P. Boucher, E. Imhoff et al., "Sevoflurane for sedation in acute respiratory distress syndrome. a randomized controlled pilot study," American Journal of Respiratory and Critical Care Medicine, vol. 195, no. 6, pp. 792-800, 2017.

[27] K. R. Famous, K. Delucchi, L. B. Ware et al., "Acute respiratory distress syndrome subphenotypes respond differently to randomized fluid management strategy," American Journal of Respiratory and Critical Care Medicine, vol. 195, pp. 331338, 2017.

[28] M. Jabaudon, P. Berthelin, T. Pranal et al., "Receptor for advanced glycation end-products and ARDS prediction: a multicentre observational study," Scientific Reports, vol. 8, no. 1, article 2603, 2018.

[29] A. Agrawal, M. A. Matthay, K. N. Kangelaris et al., "Plasma angiopoietin-2 predicts the onset of acute lung injury in critically ill patients," American Journal of Respiratory and Critical Care Medicine, vol. 187, no. 7, pp. 736-742, 2013.

[30] J. R. Le Gall, S. Lemeshow, and F. Saulnier, “A new simplified acute physiology score (SAPS II) based on a European/North American multicenter study," JAMA, vol. 270, no. 24, pp. 2957-2963, 1993.

[31] J. R. Le Gall, A. Neumann, F. Hemery et al., "Mortality prediction using SAPS II: an update for French intensive care units," Critical Care, vol. 9, no. 6, article R645, 2005.

[32] O. Gajic, O. Dabbagh, P. K. Park et al., "Early identification of patients at risk of acute lung injury: evaluation of lung injury prediction score in a multicenter cohort study," American Journal of Respiratory and Critical Care Medicine, vol. 183, no. 4, pp. 462-470, 2011.

[33] R. J. Feise, "Do multiple outcome measures require p-value adjustment?," BMC Medical Research Methodology, vol. 2, no. 1, p. 8, 2002.

[34] A. Bierhaus, P. M. Humpert, M. Morcos et al., "Understanding RAGE, the receptor for advanced glycation end products," Journal of Molecular Medicine, vol. 83, no. 11, pp. 876-886, 2005.

[35] J. Xie, J. D. Méndez, V. Méndez-Valenzuela, and M. M. Aguilar-Hernández, "Cellular signalling of the receptor for advanced glycation end products (RAGE)," Cellular Signalling, vol. 25, no. 11, pp. 2185-2197, 2013.

[36] M. A. Hofmann, S. Drury, C. Fu et al., "RAGE mediates a novel proinflammatory axis: a central cell surface receptor for S100/ calgranulin polypeptides,” Cell, vol. 97, no. 7, pp. 889-901, 1999.

[37] L. Park, K. G. Raman, K. J. Lee et al., "Suppression of accelerated diabetic atherosclerosis by the soluble receptor for advanced glycation endproducts," Nature Medicine, vol. 4, no. 9, pp. 1025-1031, 1998. 
[38] K. Wear-Maggitti, J. Lee, A. Conejero, A. M. Schmidt, R. Grant, and A. Breitbart, "Use of topical sRAGE in diabetic wounds increases neovascularization and granulation tissue formation," Annals of Plastic Surgery, vol. 52, no. 5, pp. 519$521,2004$.

[39] M. T. Goova, J. Li, T. Kislinger et al., "Blockade of receptor for advanced glycation end-products restores effective wound healing in diabetic mice," The American Journal of Pathology, vol. 159, no. 2, pp. 513-525, 2001.

[40] A. Taguchi, D. C. Blood, G. del Toro et al., "Blockade of RAGE-amphoterin signalling suppresses tumour growth and metastases," Nature, vol. 405, no. 6784, pp. 354-360, 2000.

[41] H. Zhang, S. Tasaka, Y. Shiraishi et al., "Role of soluble receptor for advanced glycation end products on endotoxininduced lung injury," American Journal of Respiratory and Critical Care Medicine, vol. 178, no. 4, pp. 356-362, 2008.

[42] M. T. Kuipers, H. Aslami, P. R. Tuinman et al., "The receptor for advanced glycation end products in ventilator-induced lung injury," Intensive Care Medicine Experimental, vol. 2, no. 1, p. 22, 2014.

[43] H. Yonekura, Y. Yamamoto, S. Sakurai et al., "Novel splice variants of the receptor for advanced glycation end-products expressed in human vascular endothelial cells and pericytes, and their putative roles in diabetes-induced vascular injury," Biochemical Journal, vol. 370, no. 3, pp. 1097-1109, 2003.

[44] A. H. Hergrueter, K. Nguyen, and C. A. Owen, "Matrix metalloproteinases: all the RAGE in the acute respiratory distress syndrome," American Journal of Physiology Lung Cellular and Molecular Physiology, vol. 300, no. 4, pp. L512-L515, 2011.

[45] C. Bopp, S. Hofer, J. Weitz et al., "sRAGE is elevated in septic patients and associated with patients outcome," Journal of Surgical Research, vol. 147, no. 1, pp. 79-83, 2008.

[46] C. S. Calfee, L. B. Ware, M. D. Eisner et al., "Plasma receptor for advanced glycation end products and clinical outcomes in acute lung injury," Thorax, vol. 63, no. 12, pp. 1083-1089, 2008.

[47] B. Zhao, Y. Chen, W. W. Sun et al., "Effect of S100A12 and soluble receptor for advanced glycation end products on the occurrence of severe acute pancreatitis," Journal of Digestive Diseases, vol. 17, no. 7, pp. 475-482, 2016.

[48] M. W. Poulsen, J. M. Andersen, R. V. Hedegaard et al., "Shortterm effects of dietary advanced glycation end products in rats," British Journal of Nutrition, vol. 115, no. 4, pp. 629636, 2016.

[49] J. Uribarri, M. D. del Castillo, M. P. de la Maza et al., "Dietary advanced glycation end products and their role in health and disease," Advances in Nutrition, vol. 6, pp. 461-473, 2015.

[50] N. Grossin, F. Auger, C. Niquet-Leridon et al., "Dietary CML-enriched protein induces functional arterial aging in a RAGE-dependent manner in mice," Molecular Nutrition \& Food Research, vol. 59, no. 5, pp. 927-938, 2015.

[51] C. Ingels, I. Derese, P. J. Wouters, G. Van den Berghe, and I. Vanhorebeek, "Soluble RAGE and the RAGE ligands HMGB1 and S100A12 in critical illness: impact of glycemic control with insulin and relation with clinical outcome," Shock, vol. 43, no. 2, pp. 109-116, 2015.

[52] K. Nakamura, H. Adachi, T. Matsui, Y. Kurita, M. Takeuchi, and S. I. Yamagishi, "Independent determinants of soluble form of receptor for advanced glycation end products in elderly hypertensive patients," Metabolism, vol. 58, no. 3, pp. 421-425, 2009.

[53] K. Fujisawa, N. Katakami, H. Kaneto et al., "Circulating soluble RAGE as a predictive biomarker of cardiovascular event risk in patients with type 2 diabetes," Atherosclerosis, vol. 227, no. 2, pp. 425-428, 2013.

[54] H. M. Colhoun, D. J. Betteridge, P. Durrington et al., "Total soluble and endogenous secretory receptor for advanced glycation end products as predictive biomarkers of coronary heart disease risk in patients with type 2 diabetes: an analysis from the CARDS trial," Diabetes, vol. 60, no. 9, pp. 2379-2385, 2011.

[55] H.-J. Park, J. Y. Baek, W. S. Shin et al., "Soluble receptor of advanced glycated endproducts is associated with plaque vulnerability in patients with acute myocardial infarction," Circulation Journal, vol. 75, no. 7, pp. 1685-1690, 2011.

[56] G. Basta, A. M. Sironi, G. Lazzerini et al., "Circulating soluble receptor for advanced glycation end products is inversely associated with glycemic control and S100A12 protein," The Journal of Clinical Endocrinology \& Metabolism, vol. 91, no. 11, pp. 4628-4634, 2006.

[57] N. Grossin, M. P. Wautier, T. Meas, P. J. Guillausseau, P. Massin, and J. L. Wautier, "Severity of diabetic microvascular complications is associated with a low soluble RAGE level," Diabetes \& Metabolism, vol. 34, no. 4, pp. 392-395, 2008.

[58] F. Peng, D. Hu, N. Jia et al., "Association of four genetic polymorphisms of AGER and its circulating forms with coronary artery disease: a meta-analysis," PLoS One, vol. 8, no. 7, article e70834, 2013.

[59] N. M. Maruthur, M. Li, M. K. Halushka et al., "Genetics of plasma soluble receptor for advanced glycation end-products and cardiovascular outcomes in a community-based population: results from the Atherosclerosis Risk in Communities Study," PLoS One, vol. 10, no. 6, article e0128452, 2015.

[60] K. H. J. Gaens, I. Ferreira, C. J. H. van der Kallen et al., “Association of polymorphism in the receptor for advanced glycation end products (RAGE) gene with circulating RAGE levels," The Journal of Clinical Endocrinology \& Metabolism, vol. 94, no. 12, pp. 5174-5180, 2009.

[61] B. I. Hudson, A. M. Carter, E. Harja et al., "Identification, classification, and expression of RAGE gene splice variants," The FASEB Journal, vol. 22, no. 5, pp. 1572-1580, 2008. 


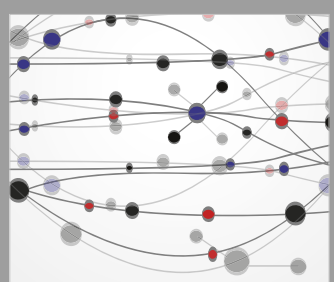

The Scientific World Journal
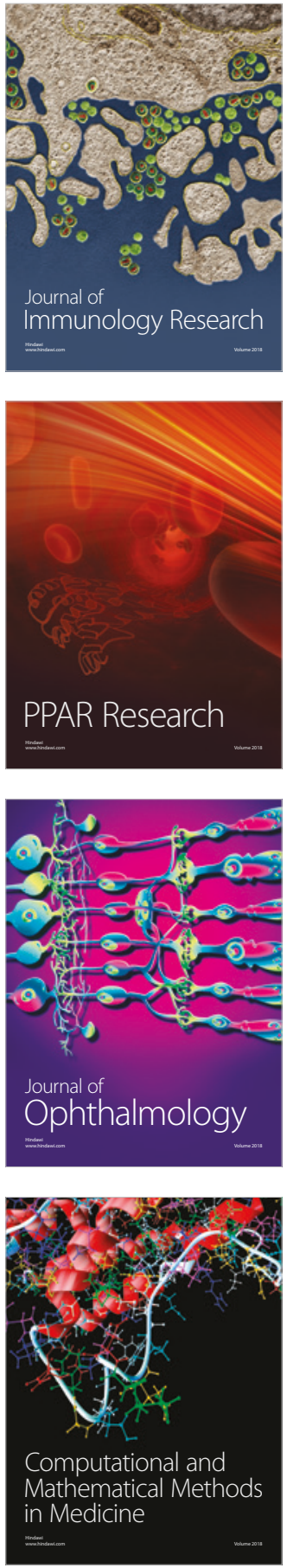

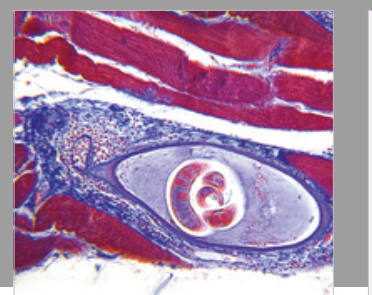

Gastroenterology Research and Practice

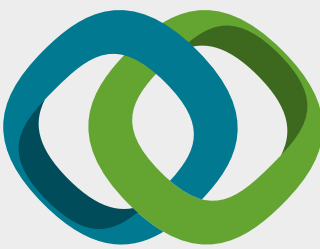

\section{Hindawi}

Submit your manuscripts at

www.hindawi.com
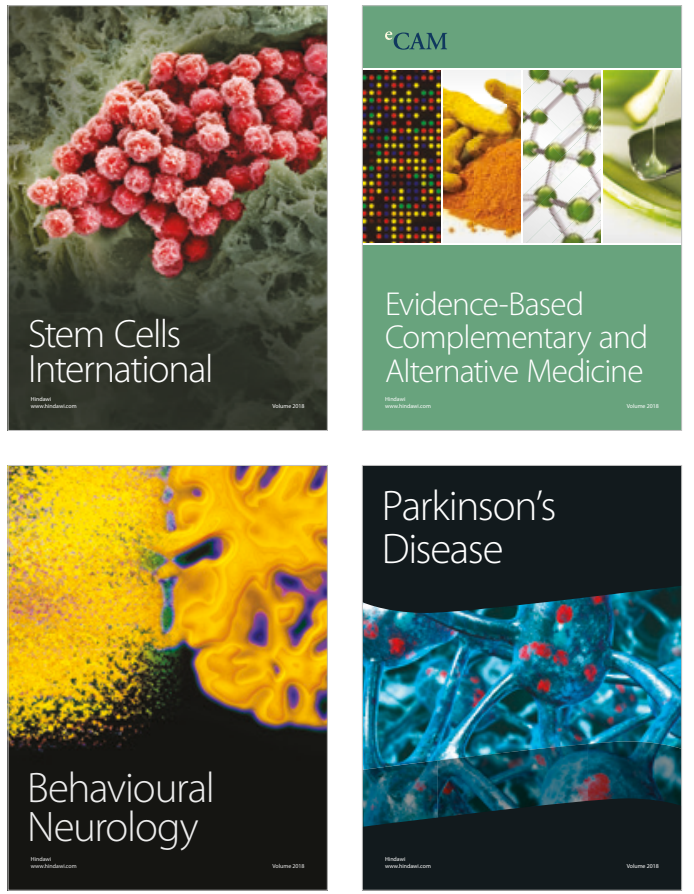

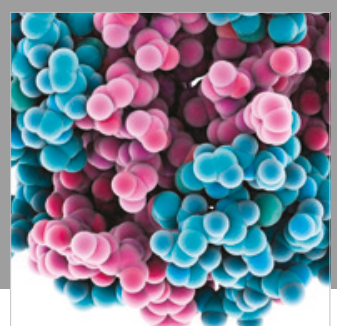

ournal of

Diabetes Research

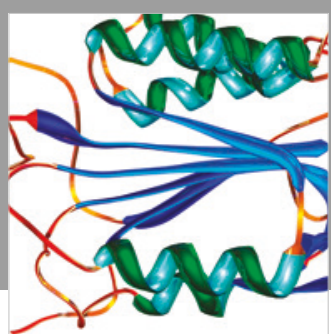

Disease Markers
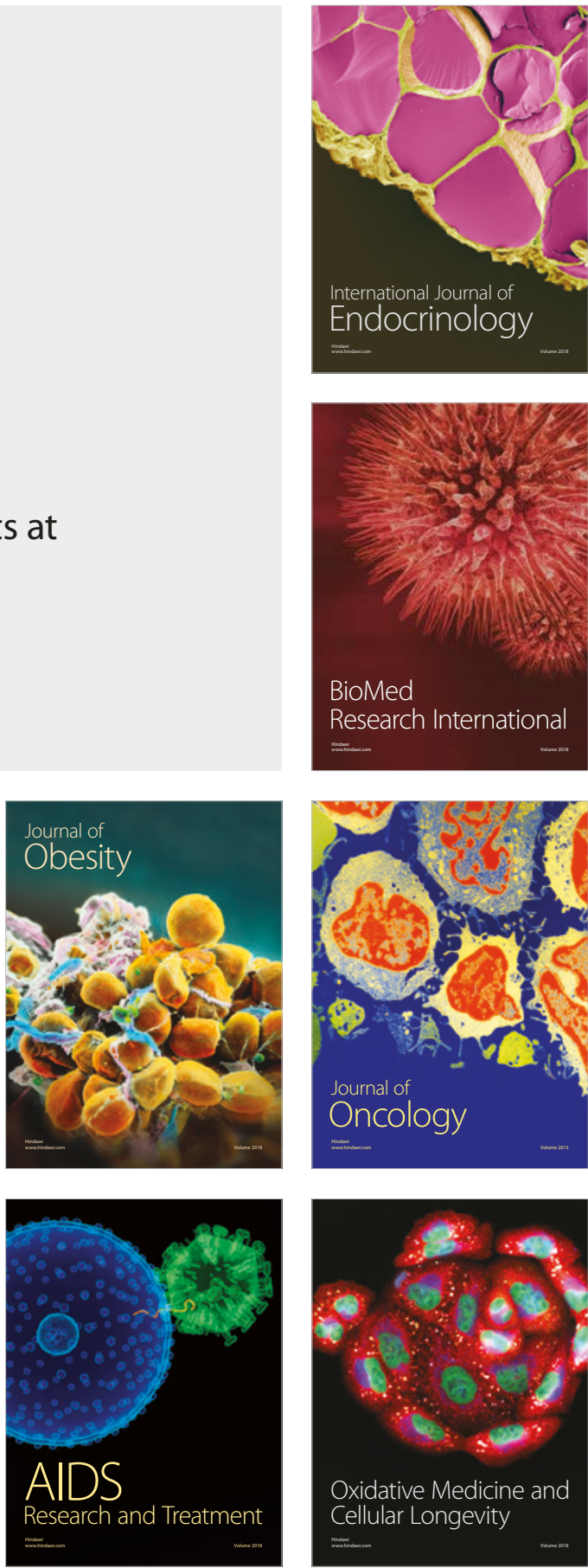